American Journal of

Health, Medicine and Nursing Practice (AJHMN)

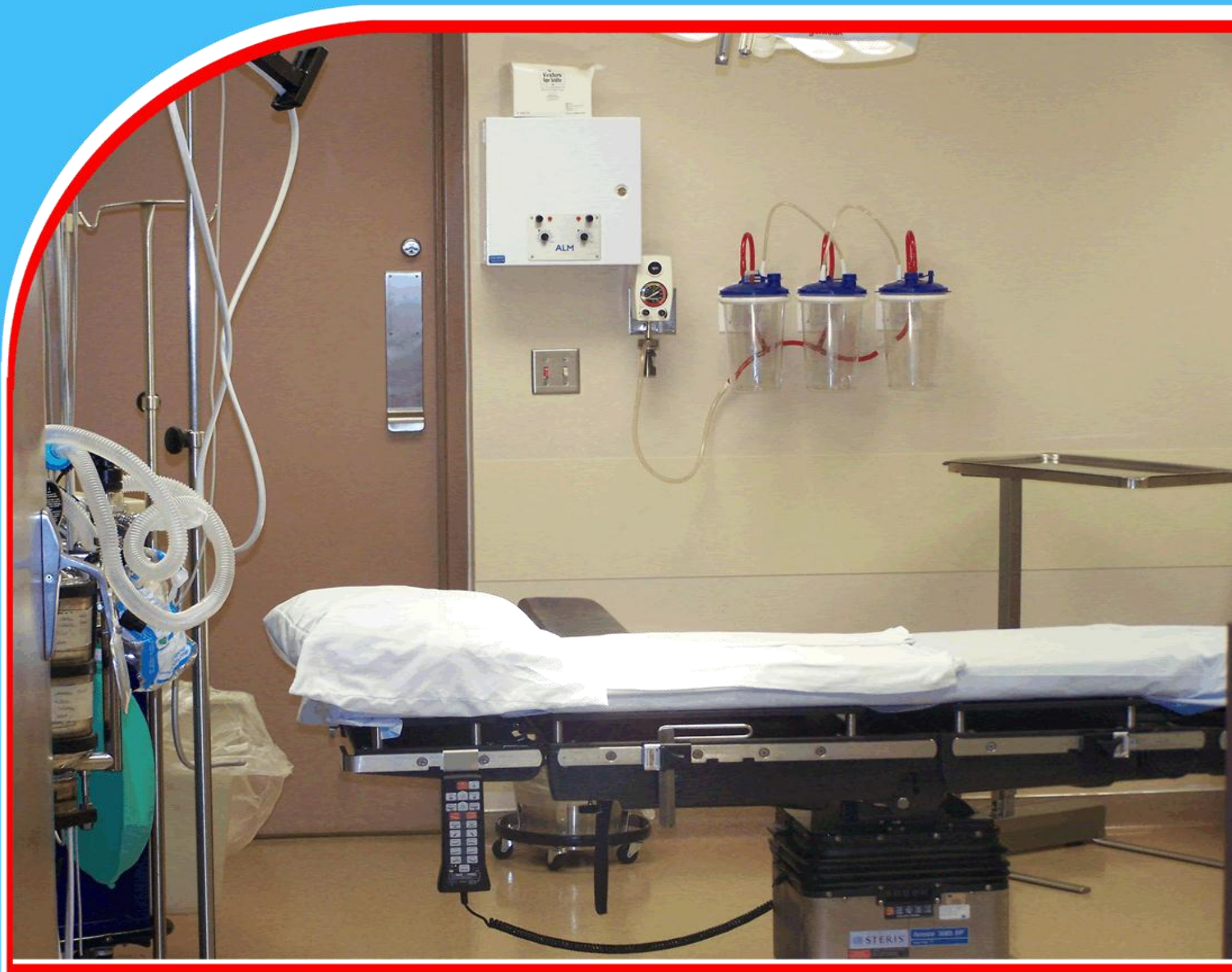

Prevalence Of Trigeminal Neuralgia In Patients With Chronic Facial Pain in Neurology Lrh Hospital Peshawar. Saad Ali, Zahwa Salam, Shakir Ullah, Mehtab Alam, and Harwindar Kumar

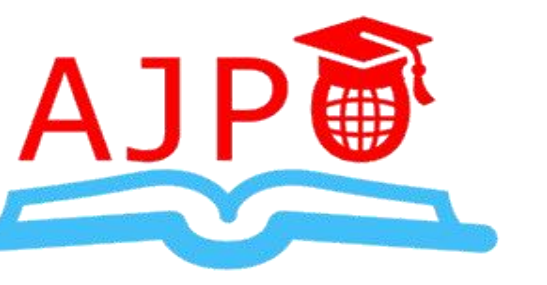




\title{
Prevalence of Trigeminal Neuralgia in Patients with Chronic Facial Pain in Neurology Lrh Hospital Peshawar.
}

\author{
${ }^{1}$ Saad Ali, ${ }^{2}$ Zahwa Salam, ${ }^{3}$ Shakir Ullah, ${ }^{4}$ Mehtab Alam, ${ }^{5}$ Harwindar Kumar \\ ${ }^{1}$ Assistant Professor, Neurology, MTI Lady Reading Hospital Peshawar. \\ ${ }^{2}$ House officer, Peshawar dental hospital. \\ ${ }^{3}$ Assistant Professor, Khyber medical University, Peshawar. \\ ${ }^{4}$ Specialist Registrar, MTI Lady Reading Hospital, Peshawar. \\ ${ }^{5}$ Medical officer, Neurology ward, MTI Lady Reading Hospital, Peshawar.
}

Corresponding author's Email: zahwasalam98@gmail.com

\begin{abstract}
Background: Trigeminal Neuralgia (TN) consist of brief periodic but severe and chronic facial pain in Facial region in single or multiple branches of the trigeminal nerve.

Objective: The objective of this study was to find the prevalence of TN in patients with chronic facial pain.

Methodology: This cross sectional observational study was conducted at Department of Neurology OPD Lady Reading Hospital, Peshawar. 46 patients with chronic facial pain were selected for the study. All data was taken on a structured Performa and was entered and analyzed using SPSS version 21. Using non probability consecutive sampling after taking approval from Ethical Committee of the hospital, study duration was 10 months from 25-1-2019 to 25-10-2019.

Results: Out of 46 patients, there were 18 (39.1\%) males and 28 (60.9\%) females. The mean age of the patients was 50.67, the Standard Deviation recorded was 11.56. Minimum age was 21 and maximum age was 67.23. Out of 31 patients diagnosed with TN had history of tooth extraction and 8 had no extraction. Out of 31 patients presented with TN, right side was involved in 24 (52.2\%) patients and left side was involved in 7 (15.2\%) patients. Mandibular never was more common in the patients with $\mathrm{TN}$ which was $37 \%$ followed by maxillary nerve $21.7 \%$, and ophthalmic nerve at $8.7 \%$. Majority of the patients $28(75.7 \%)$ belonged to the age group of 40 to 67. Females having TGN were $78 \%$ and males were $50 \%$. Right side (52.2\%) was more involved than left side. Mandibular division (37\%) was more involved than maxillary and ophthalmic division.
\end{abstract}

Conclusion: We conclude that females are more at risk of developing $\mathrm{TN}$ than males. Increasing age has a higher chance of developing TN. Right side is more involved than left. Mandibular division is more involved than maxillary and ophthalmic.

Keywords: Prevalence, trigeminal neuralgia, chronic, facial pain. 
American Journal of Health, Medicine and Nursing Practice

ISSN 2520-4017 (Online)

Vol.6, Issue 6, pp $1-7,2021$

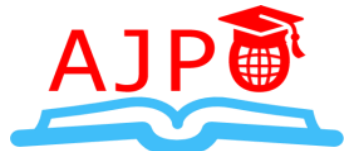

WWW.ajpojournals.org

\section{Introduction}

Trigeminal Neuralgia (TN) consist of brief periodic but severe and chronic facial pain in the orofacial region in single or multiple branches of the trigeminal nerve. This can be triggered sometimes by a simple touch and can be expressed as a sudden and frequent electric shock-like pain. Often it's is misdiagnosed and confused with dental-related problems ${ }^{1-2}$. A study showed that TN is commonly unilateral and more frequent in the older population. Its episode initially starts and end for a few seconds but in some serious cases, this pain may exist for minutes and seriously affects the day to day routine of the patient ${ }^{3-4}$.

According to the International Classification of Headache Disorders (ICHD) Trigeminal nerve is affected by paroxysms pain and there is no evidence of any neurologic disorder during clinical examination. All the patients' complaint about the same sort of attacks, the pain attacks are unexpected and has felt like stabbing, which is cursory and sudden. Causes behind facial pain are usually misdiagnosed i.e, TN is among facial pains which are often confused with other types of facial pain but for trained health care professionals it does not pose any difficulty during diagnosis ${ }^{5}$. According to the International Headache Society (IHS), TN has two different categories i.e, Classical TN \& Symptomatic $\mathrm{TN}^{6}$. If the cause such as neurovascular compression at trigeminal root is found among the patients then those patients fall in the Classical TN category. On the other hand, causes like compression exerted by the tumor, multiple sclerosis, infarction fit in the category of Symptomatic TN. A study conducted in the United States suggested that the prevalence of $\mathrm{TN}$ is more frequent in women as compared to men and showed the incidence rate of 5 in 100000 annualy $^{7}$. The incidence rate in the UK becomes higher as much as 26.8 in $100000^{8}$. An increase in age raises the chances of the prevalence among patients age 50 years and older ${ }^{9-10}$.TN can be found in children as well.

Another study provided evidence that $\mathrm{TN}$ is more recurrent in females with a prevalence of $60 \%{ }^{11}$. TN affects either the right or left side of the face but most of the patients were found to be affected on the right side of the face ${ }^{12}$. A study in Europe found a prevalence of $14 \%$ in patients having TN, complaining of neuropathic pain ${ }^{13}$. Misdiagnosis by health care practitioners confused $\mathrm{TN}$ with sinusitis and dental pain, and the prevalence of misdiagnosis touches $48 \%{ }^{14-15}$. Another study revealed that patients having multiple sclerosis in association with $\mathrm{TN}$ has a prevalence of $2 \%$. Females and Males ratio are different among patients affected by TN, multiple studies observed that $\mathrm{TN}$ is found more frequent in females rather than males with a ratio of $2: 1$.In the common population, the prevalence of $\mathrm{TN}$ fluctuates between $0.01 \%$ and $0.3 \%$, these numbers showed substantial increase depending upon health services, and the prevalence was observed $12 \%$ per $100000^{17}$.

Diagnosis of TN is made based on the patients' history and symptoms concerning the physical and neurological examination. Magnetic Resonance Imaging (MRI) is a popular and helpful diagnostic method to avoid any confusion in the treatment of TN, with the help of an MRI scan a health professional can rule out other causes i.e, multiple sclerosis and tumor that inflict pain. MRI imaging is effective to expose the seriousness of compression of the nerve by the blood vessel.

Health professionals usually prescribed carbamazepine (Carbatrol, Tegretol, etc), because of their promising results in treating $\mathrm{TN}$ as the first line of defense for treating $\mathrm{TN}$. Other drugs like phenytoin, oxcarbazepine, and lamotrigine, baclofen, etc also showed positive results as well. 
American Journal of Health, Medicine and Nursing Practice

ISSN 2520-4017 (Online)

Vol.6, Issue 6, pp $1-7,2021$

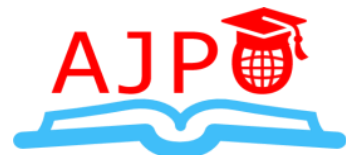

WWW.ajpojournals.org

Surgical interventions like Microvascular Decompression is the recommended surgical procedure for TN, in this procedure, the problematic blood vessels are removed or relocated from the trigeminal root so that the nerve work normally. Glycerol injection is another way of treating TN, the doctor inject sterile glycerol into the trigeminal nerve in a small amount to relieve/block pain and damage the trigeminal nerve. The needle is usually inserted through the face. Brain stereotactic radiosurgery is a technique in which the trigeminal nerve is damage with the help of radiation, which is directed by the surgeon towards the root of the trigeminal nerve. This method helps relieve pain.

\section{Methods and Materials:}

This observational cross sectional study was conducted at Neurology OPD Lady Reading Hospital, Peshawar. The study was conducted after taking written permission from hospital's Ethical Committee. The duration of the study was 10 months, from 25-1-2019 to 25-10-2019. Patients were selected by non-probability consecutive sampling technique. A total of 46 patients having chronic facial pain were selected for the study. TN was diagnosed by clinical examination, taking proper neurological history and MRI scans. SPSS version 21 was used for statistical analysis. Frequency and Charts were used for categorical data like age groups, gender, TN, tooth extraction history, facial sides and nerve divisions, Mean and SD were computed for age. Chi Square test for used for statistical significance keeping $\mathrm{P}<0.05$.

\section{Results:}

Out of 46 patients, there were $18(39.1 \%)$ males and $28(60.9 \%)$ females as summarized in table 1. The mean age of the patients was 50.67, the Standard Deviation recorded was 11.56. Minimum age was 21 and maximum age was 67 as shown in table 2. There were total $31(67.4 \%)$ cases of TN out of 46 patients. Majority of patients presented with TN belonged to the age group of 40 to 67 , which were $28(75.7 \%)$. Age groups and TN showed a significant association by applying Chi Square Test keeping $\mathrm{P}<0.05$ as indicated in table 3. Gender stratification showed that there were more females presented with TN than males. Twenty two out of 28 females (78.6\%) females had TN and 9 out of 18 males (50\%) had TN. Upon applying Chi Square Test, there was a statistically significance between gender and TN keeping $\mathrm{P}<0.05$ as shown in table 4 .

Twenty three out of thirty one patients diagnosed with TN had history of tooth extraction and 8 had no extraction. Out of 31 patients presented with TN, right side was involved in $24(52.2 \%)$ patients and left side was involved in $7(15.2 \%)$ patients as indicated in figure 1. Mandibular nerve was more common in the patients with TN which was $37 \%$ followed by maxillary nerve $21.7 \%$ and, ophthalmic never $8.7 \%$ as shown in figure 2 .

Table 1: Gender Distribution

\begin{tabular}{lcc}
\hline Gender & Frequency & Percent \\
\hline Male & 18 & 39.1 \\
Female & 28 & 60.9 \\
Total & 46 & 100.0 \\
\hline
\end{tabular}


American Journal of Health, Medicine and Nursing Practice

ISSN 2520-4017 (Online)

Vol.6, Issue 6, pp 1-7, 2021

www.ajpojournals.org

Table 2: Mean and SD of Age

\begin{tabular}{|ccccc|}
\hline Total Patients & Minimum & Maximum & Mean & Std. Deviation \\
\hline 46 & 21 & 67 & 50.67 & 11.564 \\
\hline
\end{tabular}

Table 3: Age wise Stratification

\begin{tabular}{|c|c|c|c|c|}
\hline \multirow{2}{*}{ Age groups } & \multicolumn{2}{|c|}{ TN Presence } & \multirow[t]{2}{*}{ Total } & \multirow{6}{*}{$P=0.015$} \\
\hline & Yes & Other Problem & & \\
\hline \multirow{2}{*}{21 to 39} & 3 & 6 & 9 & \\
\hline & $33.3 \%$ & $66.7 \%$ & $100.0 \%$ & \\
\hline \multirow[t]{2}{*}{40 to 67} & 28 & 9 & 37 & \\
\hline & $75.7 \%$ & $24.3 \%$ & $100.0 \%$ & \\
\hline
\end{tabular}

Table 4: Gender Stratification

\begin{tabular}{|c|c|c|c|c|}
\hline \multirow{2}{*}{ Gender } & \multicolumn{2}{|c|}{ TN Presence } & \multirow[t]{2}{*}{ Total } & \multirow{6}{*}{$P=0.044$} \\
\hline & Yes & Other Problem & & \\
\hline \multirow[t]{2}{*}{ Male } & 9 & 9 & 18 & \\
\hline & $50.0 \%$ & $50.0 \%$ & $100.0 \%$ & \\
\hline \multirow[t]{2}{*}{ Female } & 22 & 6 & 28 & \\
\hline & $78.6 \%$ & $21.4 \%$ & $100.0 \%$ & \\
\hline
\end{tabular}

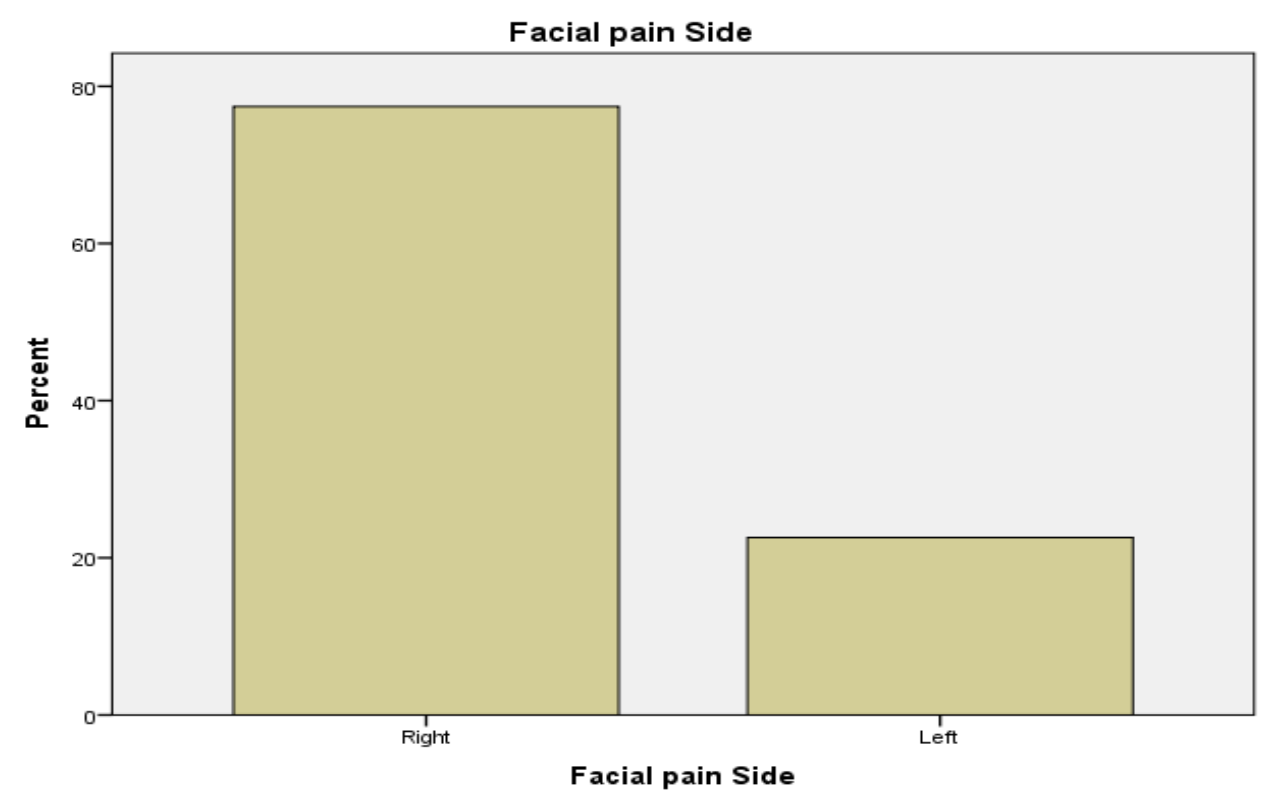

Figure 1: Presence of TN on right side and left side of patients. 


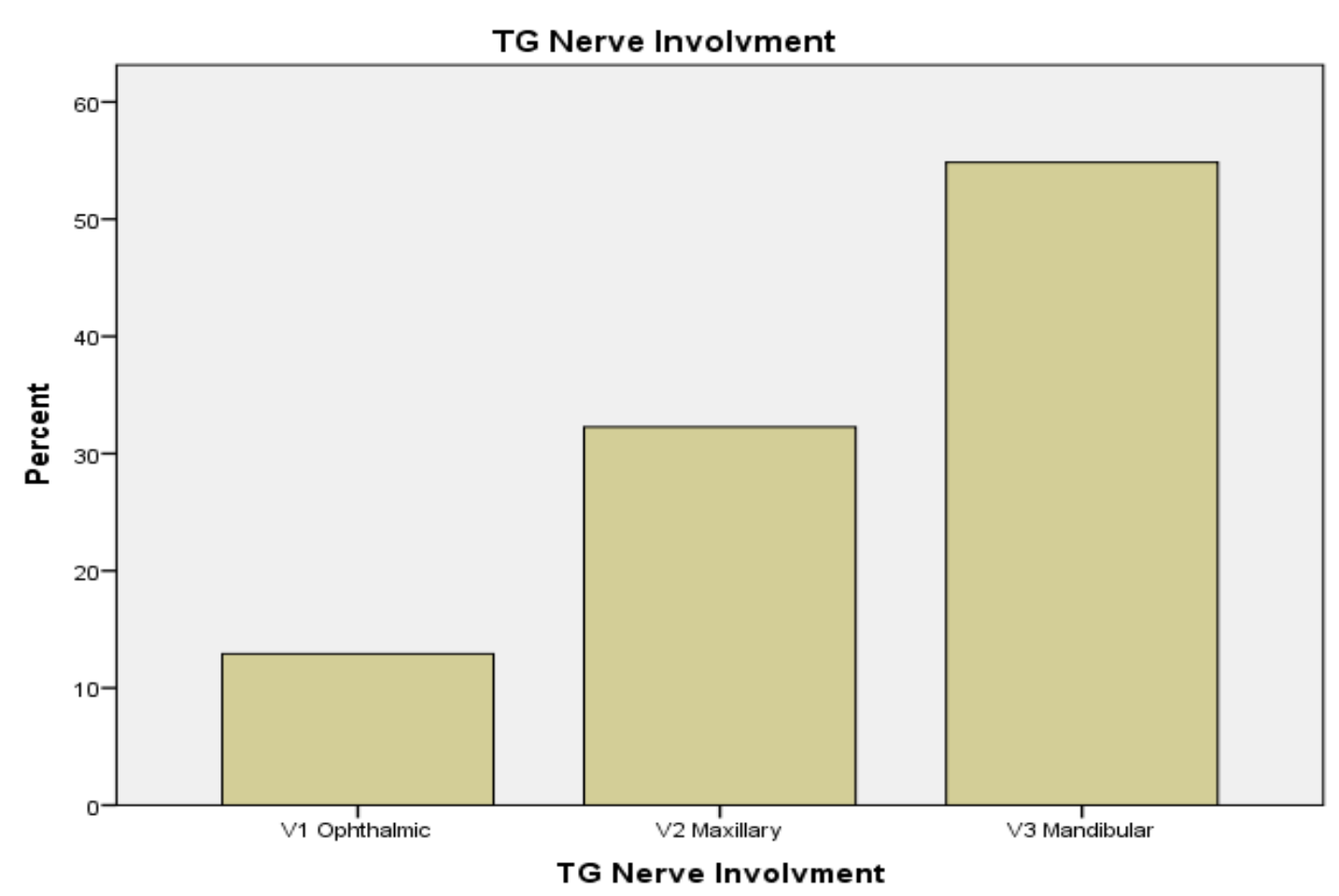

Figure 2: Presence of mandibular nerve, maxillary nerve, and ophthalmic never in patients.

\section{Discussion:}

$\mathrm{TN}$ is a rare neuropathic facial disorder which is brief in time span but causes quite severe and chronic pain in facial region of the trigeminal nerve. The pain may not last for longer durations but it can affect the quality of life on daily basis. The short episodes of TN pain can create problems in daily routines. The condition can psychological affect the patient.

This study showed a prevalence of $67.4 \%$ in total 46 patients. The prevalence of females with TN in the study was higher than the males with $78.6 \%$ as compared to males which was $50 \%$. This finding is similar to a study conducted in India ${ }^{18}$ which showed a prevalence of $58.3 \%$ in urban location and $60 \%$ in rural location as compared to male patients which showed a prevalence of $41.7 \%$ in urban and $40 \%$ in rural location. A study conducted in Egypt ${ }^{19}$ had also concluded the similar findings of females being more affected by TN than males. A Pakistani ${ }^{20}$ study also had similar findings, it showed a prevalence of $62 \%$ females and $38 \%$ males having TN. This study showed a statistical significance $(\mathrm{p}=0.044)$ between gender and $\mathrm{TN}$.

In this study, the majority of patients belonged to the age group of 40 to 67 . There were 28 (75.7\%) patients in the age group of 40 to 67. Similar findings have been report in a study conducted in Pakistan $^{21}$, the study reported that the 38 out of 50 patients belonged to the age group of $>40$ years. Similar results were also showed in another Pakistani study ${ }^{20}$ having $38.3 \%$ patients in the age group of 50 to 59 years and $53.3 \%$ patients in the age group of 60 to 80 years. This study found $\mathrm{TN}$ and age groups to be statistically significant $(\mathrm{p}=0.015)$. 
American Journal of Health, Medicine and Nursing Practice

ISSN 2520-4017 (Online)

Vol.6, Issue 6, pp $1-7,2021$

www.ajpojournals.org

Various studies ${ }^{19,21}$ have shown that TN is more common on the right side than the left side. Found that the right side $(52.2 \%)$ was more affected than the left side $(15.2 \%)$ which is in accordance to a Pakistani ${ }^{20}$ study showing right side $(78.3 \%)$ is more involved than left side $(21.7 \%)$. The study further found that mandibular division (37\%) was most commonly involved in our study tailed by maxillary (21.7\%) and then ophthalmic division (8.7\%). An Egyptian study also observed similar findings along with an Indian ${ }^{18}$ and Pakistani ${ }^{19}$ study. It is therefore suggested that careful clinical examination and history are important for proper diagnosis of $\mathrm{TN}$ and identifying the nerve involved which will lead to adequate treatment of TN.

\section{Conclusion:}

The study conclude that TN is more common in the increasing age group. Females were more at risk of developing TN than males. Right side of the face was more involved in TN than left. Mandibular Division was seen to be more involved than maxillary and ophthalmic division.

\section{REFERENCES:}

1. Headache Classification Committee of the International Headache Society (IHS). The International Classification of Headache Disorders, $3^{\text {rd }}$ edition (beta version). Cephalalgia. 2013;33(9):629-808.

2. Eller JL, Raslan AM, Burchiel KJ. Trigeminal neuralgia: definition and classification. Neurosurg Focus. 2005;18(5):E3.

3. Joffroy A, Levivier M, Massager N. Trigeminal neuralgia. Pathophysiology and treatment. Acta Neurol Belg 2001;101:20-5.

4. Ziegeler, C.; May, A. Facial presentations of migraine, TACs, and other paroxysmal facial pain syndromes.Neurology 2019, 93, e1138-e1147.

5. Anonymous. The International Classification of Headache Disorders: 2nd edition Cephalalgia 2004; 24 Suppl 1:9-160.

6. Katusic S, Beard CM, Bergstralh E, Kurland LT. Incidence and clinical features of trigeminal neuralgia, Rochester, Minnesota, 1945-1984. Ann Neurol 1990;27:89-95.

7. Hall GC, Carroll D, Parry D, et al. Epidemiology and treatment of neuropathic pain: the UK primary care perspective. Pain 2006;122:156e62.

8. Loh HS, Ling SY, Shanmuhasuntharam P, Zain R, Yeo JF, Khoo SP, et al. Trigeminal neuralgia. A retrospective survey of a sample of patients in Singapore and Malaysia. Aust Dent J 1998;43:188-91.

9. Darlow LA, Brooks ML, Quinn PD. Magnetic resonance imaging in the diagnosis of trigeminal neuralgia. J Oral Maxillofac Surg 1992;50:621-6.

10. Bennetto L, Patel NK, Fuller G. Trigeminal neuralgia and its management. BMJ 2007;334:201-5.

11. Bagheri SC, Farhidvash F, Perciaccante VJ. Diagnosis and treatment of patients with trigeminal neuralgia. J Am Dent Assoc 2004;135:1713-7. 
American Journal of Health, Medicine and Nursing Practice

ISSN 2520-4017 (Online)

Vol.6, Issue 6, pp $1-7,2021$

www.ajpojournals.org

12. McDermott AM, Toelle TR, Rowbotham DJ, et al. The burden of neuropathic pain: results from a cross-sectional survey. Eur J Pain 2006;10:127e35.

13. Drangsholt M, Truelove E. Trigeminal neuralgia mistaken as temporomandibular disorder. J Evid Base Dent Pract 2001;1:41e50.

14. Koopman JS, Dieleman JP, Huygen FJ, et al. Incidence of facial pain in the general population. Pain 2009; 147:122e7.

15. Kim JS, Kang JH, Lee MC. Trigeminal neuralgia after pontine infarction. Neurology1998;51(November (5)):1511-2.

16. Yadav S, Mittal HC, Sachdeva A, Verma A. A retrospective study of 72 cases diagnosed with idiopathic trigeminal neuralgia in indian populace. J Clin Exp Dent 2015; 7(1).

17. Katheriya G, Chaurasia A, Khan N, Iqbal J. Prevalence of trigeminal neuralgia in Indian population visiting a higher dental care center in North India. Natl J Maxillofac Surg 2019;10:195-9.

18. El-Tallawy HN, Farghaly WM, Rageh TA, et al. Prevalence of trigeminal neuralgia in AlQuseir city (Red sea Governorate), Egypt. Clin Neurol Neurosurg. 2013;115(9):1792-1794

19. Alam J, Channar K A,Wahab N U, Dal A Q,Warriach R A, Khan ZA. Clinical presentation of various cases of trigeminal neuralgia. J Pak Dent Assoc 2012, 20 (02), 85 - 89

20. Shah SA, Murad N, Salaar A, Iqbal A. Trigeminal neuralgia: analysis of pain distribution and nerve involvement. Pakistan Oral Dent J. 2008;28(1):37-41. 